\title{
PROPERTY ECONOMICS AND METHOD: FORMALISING THE METHODOLOGICAL PARAMETERS FOR THE DISCIPLINE
}

\author{
GARRICK SMALL \\ University of Technology, Sydney
}

\begin{abstract}
The methodological debates within economics are reviewed. Methodology as the theory for attaining knowledge is contrasted to method. Various methods are reviewed in terms of their suitability for the discipline. Methodology as an independent science and its relationship to the other sciences is reviewed along with property economics. The limitations of the dominant methodological approach to the discipline are surveyed and related to larger movements in contemporary thought.

The tendency to rely overly on empirical method is shown to create unnecessary shortcomings. A broader approach is recommended, incorporating current methods, but covering their shortcomings is suggested.
\end{abstract}

Keywords: Property economics methodology, metaphysics, epistemology, history of economic thought, ethics and economics, history and philosophy of science, classical sciences

\section{INTRODUCTION}

Deborah Levy (2003) observed that the overwhelming content of scholarly journals in the property economics discipline were positive studies dominated by quantitative analysis. She argued that this resulted in an unnecessary bias in the discipline against other approaches to expanding its body of knowledge. Alfred Marshall $(1890,24-7)$ had previously defined the science of economics methodologically as a positive science; one that would provide insights into the behaviour of economic systems for the better design of policy. Unfortunately, the positive performance of the science has never met his expectations. Property economics has largely inherited the Marshallian character, along with its shortcomings. The transition from political economy to economics was largely a methodological shift which considerably simplified the discipline. Unfortunately the simplification has proven as problematic for the discipline as it has been for debate over the question of methodology itself. Currently, many research publications use the term 
"methodology" where the authors mean "method" and the question of methodology is almost entirely avoided.

This paper will define methodology and locate it within the sciences. It will then review the current methodological premises of property economics and relate them to the level of success in materially adding to the essential body of knowledge of the discipline. Finally it will make recommendations for expanding the methodological possibilities for the discipline.

\section{ECONOMICS, SCIENCE AND METHODOLOGY}

Economics prides itself as being a science. To understand what this means and what methodological implications it may have for property economics, it is first necessary to resolve what science means and why scientific knowledge is important.

Humans devote considerable resources to trying to understand how things work, from how atoms behave, to mathematical puzzles, to the reasons for wars. People have a latent confidence that it is possible to know how things work and if their understanding is accurate it will help them shape their future. Much of our life is lived under the belief that this is both possible and largely achieved, at least in the realm of our immediate action. There is also a latent confidence that things are orderly; that an insight found in one situation will hold in a similar situation; that the world is not like a nightmare where things metamorphose constantly in unexpected ways. In short, our lives are lived largely under the naïve confidence that countless aspects of the external world are orderly, knowable and known, that our understandings of them correspond accurately with the reality of their being. These are the necessary premises for any scientific knowledge, and despite ultimately being unproven, even the sceptical Enlightenment philosopher David Hume admitted that he accepted them for the greater part of his life (Hume 1777). Even though we are sometimes mistaken in our understanding of the world, the occasional error does not negate the overwhelming evidence of the stability of the external world and our ability to know it. Science may be defined as the pursuit of certain knowledge through cause. The fundamental purpose of science is to make available to humanity a true understanding of how things work - what causes the various aspects of our world to behave as they do. It is only through a genuine knowledge of what causal processes are at work producing and changing the world, that humans can manage their situation reliably.

Knowledge was defined by Plato as justified true belief. Humans believe many things, but most beliefs are only opinions. The difference between an opinion and knowledge is that the latter is tested and proven, whereas an opinion rests on something less reliable, even though it may chance to be true. Truth is central to science and to knowledge. Both are composed of statements about the world that accurately describe it. To be true, a statement must be accurately conformed to the reality it describes. This means truth is the test of accuracy between the statements people hold as ideas and some other reality. The reliability, or quality, of a statement is its truth. Statements about the external world cannot be made true by human action, they can only be found or tested to be true by 
human enquiry. This is important to recognise as all science rests upon it, yet there has been a rising trend for modern and post-modern thinkers to claim that truth is manufactured (Foucault 1976).

For economics to be a science it must aim at providing certain knowledge regarding the way humans act in the marketplace. This does not necessarily mean precise knowledge, given the possible complexity of human action, but it does mean an accurate mapping of the parameters of human economic action into some intelligible form. In many cases, science uses the language of mathematics to map causal relationships. While this is largely adopted within economics, there are other media available such as narrative. The classical economists used words, not mathematics to describe economic phenomena and while much of it can be converted into a mathematical form (such as Ricardo's law of rent), in many cases it is unnecessary. Much important natural science also exists as nonmathematical knowledge, for example water is a colourless odourless liquid at standard temperature and pressure. In developing the science of property economics, the error of considering all knowledge to be in the form of mathematics should be avoided. The aim is to gather statements about the nature and cause of various aspects of human behaviour regarding property that conform to reality. The better the set of these that is available, the more useful the discipline will be in practice.

\section{METHOD AND METHODOLOGY}

The way that statements are tested for conformity to reality is the method adopted to sift knowledge from opinion. Different methods are appropriate for different topics or types of science. The methods appropriate to increase knowledge in mathematics is quite different to that used in astronomy. The study of which methods are appropriate for different categories of human enquiry is the science of methodology. Methodology is the study of which methods, or classes of methods, are most effective in finding the truth of statements about the world. Like the names of some other sciences, the word methodology may also be used as common noun to denominate particular approaches to method, usually on the basis of metaphysical or epistemological premises as well as the characteristics of the science being examined. Feminist methodology for example refers to a class of methods that share common theoretical foundations regarding how the truth of certain types of statements can be tested and it is particularly useful in some social sciences.

Method refers to the specific procedure being followed through a research or scholarly examination. It is characterised by an absence of deep theory regarding the testing of statements and an emphasis on the specific pattern of tasks that will be performed to test some hypothesis. It is like the specific recipe that is to be followed, whereas methodology is an exploration into why the recipe works. For specific research tasks method is extremely important, especially for replication, but this is not methodology, even though all methods are adopted following implicit methodological beliefs. 
In recent times there has been a trend towards an extremely narrow methodological position. Modernity as a system of thought began in the sixteenth century. Niccolae Machiavelli has been credited with ushering in modernity and has been given the title "Father of modernity." His political thought was based on observation, not ethical reflection. His method was to observe strategies that led to political success and systematise them as advice for his Prince (Machiavelli 1985). He replaced conventional ethics with practical recommendations drawn from observation. David Hume developed this approach when he suggested that his goal was to "... attempt a like reformation in all moral disquisitions; and reject every system of ethics, however subtle or ingenious, which is not founded on fact ${ }^{1}$ and observation" (Hume 1777, n.138 p175). This approach followed from Hume's belief that the only things that could be known were derived from observation.

This transformation is central to property economics. Whereas economic thought was explored as a practical science within moral philosophy from Aristotle to the beginning of the twentieth century, Marshall transformed it into a Humean quasi-natural positive science.

Several terms are used in connection with this approach. Empiricism is the belief that all knowledge proceeds from experience or observation. Experiments are controlled experiences. Positivism is the belief that the only things that exist are things that can be seen. When a science is based on empirical knowledge it is referred to as a positive science; positive in this context refers to arbitrary observable facts that are put, or posited, before the observer. Positivism is a theory of existence, or a metaphysical theory, while empiricism is a theory of knowledge, or an epistemological theory that necessarily follows from positivism. The current discipline of economics is a positive science which means that all of its body of knowledge is derived from positive experience - observations of the behaviours of various economic actors and markets.

Aristotle is credited with being the first empiricist. He believed that knowledge was formed by observing particular things and events, from which the person abstracted general truths. Although Aristotle believed that all knowledge started with observation, he placed clear emphasis on abstraction, and deduction. For Aristotle, the observation phase was only pre-science, the really useful knowledge was the formal abstraction that was deduced from it. This is still the method of science, however the emphasis has shifted considerably onto the empirical component of learning at the expense of abstraction and deduction. Several problems arise from this change of focus.

Many things are not known as a result of observation. Mathematicians understand the behaviour of surfaces in poly-dimensional space, even though it is impossible to observe them. They also understand imaginary numbers, which are necessarily beyond observation. Not only are these mathematical concepts known, they have found many useful applications in engineering and science. In human relationships love, hatred and

\footnotetext{
${ }^{1}$ Fact here has a technical meaning, it refers to a contingent truth about the world as it is, for example "Australia is in the southern hemisphere" is a fact.
} 
even justice are not observed, only actions that somehow manifest them. If things cannot be known except by observation, then knowledge of all of these are problematic. As a result their treatment has become ambiguous at best.

Even more subtly, Hume rejected the possibility that humans could know cause, believing rather that we are only aware of common conjunctions of observable events. This cuts to the core of what science aims to achieve. Many methods in science now focus only on correlations, not understanding of cause. If all that humans can know are common conjunctions of observable events, then theory becomes impossible and irrelevant. This is reflected in the tendency of much recent research, especially in property economics, to concentrate on positive data and statistical inference of common conjunctions. However, it seems to be simultaneously refuted by the persistence with which people strive to try to attach theories to observations. More troubling is the fact that many of the theories that are accepted as foundational to the discipline are not based on positive empirical support. Among these are the fundamental supply (Jones 1976) and demand (Working 1927) functions that form market theory and widely accepted urban economics theories, such as location theories (Harvey 1987). Perhaps one of the most alarming cases is that of the relationship between interest rates and inflation where economic theory (Samuelson 1975) suggests should be an inverse relationship is flatly refuted by the inflation premium theory of finance (Wilson and Keers 1990) that suggests they should correlate. The data shows limited support for both, which also infers their mutual logical rejection through modus tollens ${ }^{2}$ in the absence of a more comprehensive understanding.

Unfortunately, Hume's epistemological proposition contains its own refutation. If cause cannot be known then logical cause is definitely beyond the reach of human understanding and all logical deduction is meaningless. In short, this means that the word "therefore" can never be used, or for that matter any logical inference. All that humans can exchange are statements of observation and common conjunction. Hume's text is built on logical inferences and his empirical epistemology is not grounded on observation for although it is possible to observed specific instances where observation is the basis for some knowledge, it is impossible to observe conclusively that nothing can be known that is not the result of observation. This is so for at least two reasons. Firstly, it is impossible to be privy to all possible observations, hence it would always be possible that an observation not personally experienced could supply knowledge of cause. Secondly, the very structure of his proposition relies on implicit metaphysical definitions of his terms and characteristics of them that are not experienced. Hume's epistemological position is knowable only using an epistemology that differs from it, therefore it cannot be valid on its own terms. Unfortunately, this has not stood in the way of it being adopted as the bedrock of modern thought.

\footnotetext{
${ }^{2}$ Modus tollens is the logical strategy whereby one counterexample is sufficient to refute a theory. In this case empirical support for either theory implies the rejection of the other and since both have instances
} 
Emanuel Kant closely followed Hume, but sought to soften some of Hume's obvious shortcomings without leaving the general methodological framework of modernity. $\mathrm{He}$ also succumbed to conclusions that refuted his basic epistemology when he suggested that moral action should be guided by principles that could be rationally adopted as universal moral laws (Kant 1785). Kant did not believe that moral universals could be known with certainty and appeared to doubt their very existence. His moral process relied on observations and inferences on the implications if the principles people adopted for specific actions were generalised for all. Kant's method ran as follows: if principle A was adopted by all, and past experience suggests that it would cause effect B which would not be good, then principle A should be rejected as a guide for action. Kant was comfortable with logical cause, but if the nexus between A and B was found to hold in all cases, which would be necessary for it to hold up as a potential universal law, then one could easily ask why it would not be a universal law. Kant would reply that all observation is coloured, therefore suspect, so nothing can be known as it is, so all belief is provisional. But then the conclusion that is Kant's categorical imperative would itself be only provisional. It also suffers from the defect of not being based on experience and tends to rely on implicit agreement of what 'good' means. Good is a fundamental aspect of moral thought, but it is in large measure beyond the reach of empirical methods.

It is not necessary to go further into the epistemology of modernity beyond pointing out that narrow empiricism has considerable theoretical and practical limitations. It is suitable for some circumstances, but is not sufficiently comprehensive to explain all of the valid possibilities for the acquisition of knowledge. To better understand the various types of enquiry possible within science it is important to appreciate the various sciences and their interrelationships.

\section{THE CLASSICAL ARRANGEMENT OF THE SCIENCES}

David Hume is amongst the many thinkers who have considered the interrelationships between different areas of human understanding. Aristotle and the classical philosophers who developed his thought recognised that there were a variety of different areas of human knowledge. If these are classified according to their objects, a listing of various sciences results. If there is genuine knowledge in the discipline of property economics, then it will fall into one of these areas and be a genuine science.

The classical major divisions of the sciences are shown in Figure 1 that groups the sciences under three heads: natural sciences, practical sciences and queen sciences. The natural sciences investigate the natural world for its own sake. The practical sciences pursue knowledge regarding the application of knowledge for human purposes. The queen sciences, also known as sciences of review, are disciplines that are used in the pursuit of other sciences. The methodological requirements of each can be better understood when they are explicitly recognised to have differing objectives. 
Natural sciences, such as physics and chemistry, suit the classical Aristotelian approach of observation, abstraction and generalisation. This method has been developed into what is now known as scientific method, though the latter places emphasis on observation and the title is unfortunate as it suggests that it is the appropriate method for all sciences. The physicist or chemist observes something in the world, from this the underlying principles are abstracted and generalised to be applied to other circumstances. For example, the physicist may observe that force causes a body to accelerate. From this, the physicist may deduce the abstract operation of force on physical bodies. This principle is learned from particular empirical instances, but the abstract notion of the action of force on bodies may be applied to any force acting on any physical body. The knowledge gained can then be applied to any future situation as a general insight of physics. In many cases if observation is equivocal the conclusion may be only held as a theory that will be later tested by further observations under different circumstances.

The insights of natural science are investigated for their own merit, not because of any direct benefit for human life or community. When applications are explored, such as in engineering, medicine or economics, the sciences are practical. Practical sciences usually have a moral component because they are concerned with doing things for people and these will be pursued following some notion of what is good for people. The engineer may build a bridge using the insights of physics and other natural sciences, but the design and execution of the construction may have other issues, such as cost efficiency and environmental impact. The engineer has to balance the project to give the best result to the community and this will include ethical, or moral, issues. All of the professions are practical sciences. Mainstream economics has the moral system of utilitarianism embedded within it and although Alfred Marshall attempted to separate its ethical purpose from its method of enquiry, the result is at least comparable to that of engineering. Strictly speaking both are amongst the applied sciences-practical disciplines that apply natural sciences for the good of the community. It will be argued that the natural sciences that economics uses include the social sciences of psychology and sociology.

The queen sciences are sciences of review-they are used to qualify the other sciences. Mathematics is the best known queen science and is the most evident instance of the inappropriateness of positivism as a comprehensive position. Mathematics is primarily pursued for its own merit like the natural sciences. Its object is an understanding of the behaviour of numbers and it is closely related to geometry, especially through coordinate geometry. Its application tends to be for the development of many of the other sciences, including most of the natural and practical sciences. The physicist investigating the effect of force on a mass better understands the resulting acceleration when observations are analysed using mathematical and statistical tools and the abstraction is in the form of a mathematical relationship, in this case $F=M A$ (force=mass $x$ acceleration). With this general mathematical relationship understood an engineer can design many things including engine sizes for vehicles or the parameters for industrial presses. 
As well as the mathematical sciences (mathematics, statistics, geometry, etc) the various branches of philosophy are queen sciences. All human thought relies on logic. Each science has its metaphysical foundations, usually beginning with the natures of the objects, but often extending into more complex questions of being. Moral thought, although a distinct discipline, tends to have a place in qualifying most aspects of the practical sciences.

Figure 1: The Classical Organisation of the Sciences.

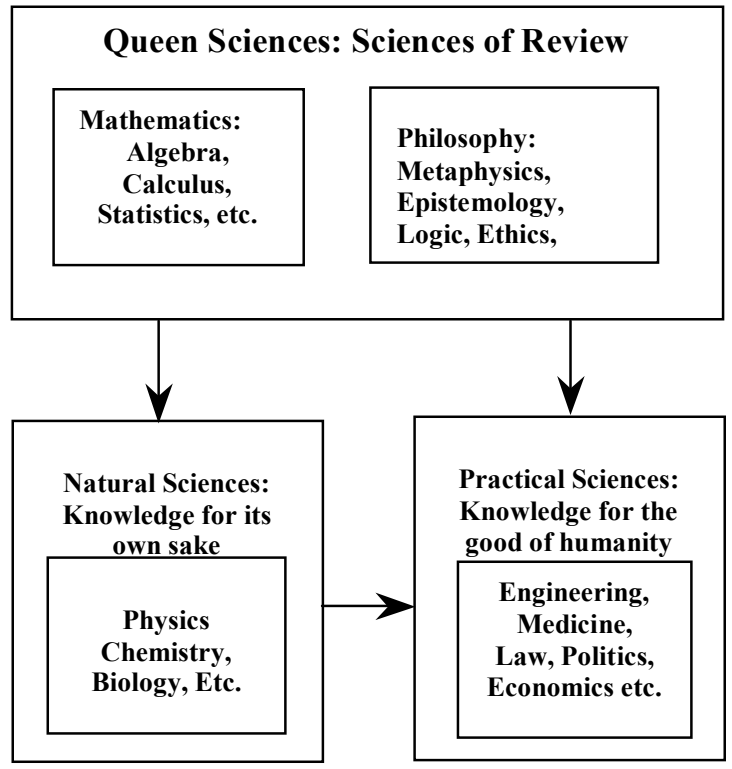

Source: Ashley (2003)

\section{METHODOLOGY AND THE DIFFERENT SCIENCES}

It has been pointed out that empirical scientific method suits the natural science, but is extremely limited for the mathematical sciences. By contrast, the insights of mathematics are known with a greater certainty than those that fill texts on the natural sciences. One can be more certain of two plus two equalling four than of Newton's laws of physics or the classification of living creatures. If this is the case then at least two distinct approaches exist for the gaining of certain knowledge, one suited to the natural sciences and the other to the mathematical sciences. 
Arguments have been put forward regarding the empirical nature of mathematics ${ }^{3}$, but these only reach the most elementary levels of the discipline. While some children may benefit from seeing elementary addition facts proven by physical cases, few people bother to check that one hundred cubed is one million by counting. No one in their right mind would check one million cubed empirically, but this is what an empirical/positive theory of mathematics would demand. The research possibilities within positive mathematics are boundless, but not very interesting. An understanding of the natures of the terms involved (values of numbers, meanings of operations and equality, etc.) enables mathematicians to deduce with certainty new functions and operations neither based on observation, nor amenable to it.

The metaphysics of mathematics is curious and bears on its methodology. Mathematical notions do not exist in the real world, but they have an intelligible, meaningful, existence. A dog may see more or less, but it appears that a dog cannot see number. We may see two apples, but we do not see the number two. It requires our mental capacity of abstraction to recognise work with numbers. Once we are working on the abstract level, no further observations are necessary. The important aspect of working on the abstract level is to understand the concepts that populate it.

Even physical things have abstract aspects. We may sit on a chair and see a chair, but the concept of chair is abstract and is somehow shared by all chairs. In writing about a chair no physical instance of chair is necessarily being considered, yet it can be meaningfully discussed. Hence we can plan the number of chairs required for a conference without being concerned about their appearance. A considerable amount of scientific knowledge can be developed without recourse to empiricism. A structural engineer can design a massive structure by simply knowing the character, or nature, or the various components that will make it up.

The natures of things form a major part of the science of metaphysics. Obviously, every science is concerned with the natures of particular things. The physicist is concerned with the nature of physical bodies and the nature of motive influences such as force and energy. A chemist is interested in the natures of chemicals and nature of their interactions. Metaphysics therefore informs all sciences through what it can supply about the behaviour of natures. Like mathematics, metaphysics is a purely intellectual science, but upon it all science and in fact all human discourse, rests. Metaphysics has the further distinction according to Aristotle of being the only science that can prove its own premises. For these reasons it has been dubbed the first science.

The methodology appropriate to metaphysics is therefore similar to that for mathematics, in that empiricism is of only minor importance, even though the knowledge available to metaphysics has a certainty considerably greater than that of the natural sciences. As the first science, the quality of one's metaphysics forms the foundations for all other sciences. In practice few people are aware of the metaphysical assumptions they operate

\footnotetext{
${ }^{3}$ Hume argued this in his Enquires in separate places for both mathematics and geometry. Its acceptance is implicit in the way Mathematics is taught in primary school in Australia.
} 
within even though every science and every thought has its metaphysics. Despite this, modernity generally prefers to ignore metaphysics as a discipline. This may be traced to David Hume who complained "All this is metaphysics... .. That is enough; there needs nothing more to give a strong presumption of falsehood" (Hume 1777, n.239 p289). Hume was not alone in his denunciation metaphysics as a discipline, but the articulation of his position has been adopted as the reference text for scepticism about this philosophical discipline. Hume used his narrow epistemological view to conclude that since metaphysics could not be observed it did not exist.

Although Hume's position has always been controversial, it has generally been accepted. The twentieth century has seen calls for a review of metaphysics as a significant element in human understanding including Richard Weaver's claim that property remains as the last metaphysical right of civilised people (Weaver 1948). Lawrence Boland has gone further with respect to economics when he stated that "Fifty years ago metaphysics was considered a dirty word but today most people recognise that every explanation has its metaphysics." (Boland 1997, p.81). Boland's comment was part of a careful study of the methodology of economics and his observations are particularly pertinent for property economics. It is sufficient to conclude at this point that metaphysics appears due for a reentry into the methodology of the property economics discipline.

Moral science, or ethics, is another queen science that has had a rough ride through modernity. Whereas metaphysics was gutted and dumped, ethics has too high a profile to be ignored. This has not protected the methodological situation of ethics. As a pure science philosophers such as Aristotle used the classical methodology of observation, abstraction and generalisation with considerable emphasis on working with the abstracted notions or natures. Hence Aristotle began with an exploration of the nature of happiness as the end of human action and used this together with an understanding of human nature to deduce ethical conclusions. Many of these did not need direct observation. It is not necessary to observe human mutilation and torture to conclude that it does not contribute to happiness. As a science of review, ethical principles may be used as a methodological component in the development of practical sciences. Again, ethical aspects of the practical sciences do not necessarily need direct observation in order to be known with certainty if the ethical principles are certain.

When ethics is grounded in classical metaphysics it tends to contain an objective dimension that is as constant as the natures involved in its construction. This is not to say that it is entirely objective but rather that it cannot be entirely subjective. This has proven to be an uncomfortable proposition down through time. The sophist Protagorus asserted that Man is the measure of all things (Hirsch 2002) thereby suggesting a methodology for ethics that is entirely subjective. It earned the ire of Aristotle's intellectual forebears, Socrates and Plato. Plato's Republic was largely directed to explaining the foundations of justice and in doing so he had to detour through fundamental metaphysical issues to establish his methodological framework (Plato 1987).

Aristotle's system of ethics was built on objective principles derived from the metaphysical nature of things, but employed with a level of subjective practicality or 
prudence. Aristotle would note that there are elements of human nature that do not change: humans have life, they are intelligent, they are social animals and they can exercise choice in selecting behaviour. While some particular humans may lack some of these characteristics, when they do it is because they are atypical or lacking. Aristotle could take characteristics like these to conclude that if a human being has life and another takes it away without good cause, then the latter act is objectively improper. Reasoning like this makes possible some ethical principles that are unchanging, even if they are rejected by some specific individual or group. This is not to say that culpability for particular instances of violation is not modified by the circumstances of the situation. In this way the fundamental methodology of ethics has a twin character, some pure ethical reasoning is most appropriately done deductively following the implications of human nature, while some practical ethical issues require attention to the empirical circumstances.

The methodology of ethics was at the heart of the initiation and development of modernity and the debate over the metaphysical foundations of ethics can be traced through the major contributors. Machiavelli's project in The Prince was largely to establish a predominantly empirical ethical system, erected largely in opposition to the prevailing realist system that was grounded on metaphysics. Machiavelli did not reject the intrinsic evil of certain moral acts, such as dishonesty and cruelty, but he recommended that his prince should not be above doing them in order to achieve political ends. Hume took Machiavelli's position further by claiming that is was impossible to know if acts were moral or not from anything more than direct experience. While Machiavelli placed political success as a higher good that justified objectively evil acts, Hume claimed that there were no objectively evil acts, only the human reaction of disapprobation that collectively earned particular acts the label of being perceived as evil.

Kant's text on ethics makes an explicit appeal to metaphysics, but the result is really a reformulation of metaphysics along phenomenological lines. While he was critical of Hume's radical subjectivity, he replaced Hume's disapprobation of the collective as the bedrock of moral worth with the rational reasoning of the moral actor. Kant argued that if the moral actor could conclude reasonably that the principle underlying a particular act could be adopted as a universal law, then the act was morally licit. Kant was less clear as to why such a moral enquiry did not have as its end the recognition of an actual universal law. Surely if deductive reason concluded that a principle for action could be adopted as a universal law, then it would hold universally, simply because of the terms and logic of its own construction. The wrinkle in Kant's system is that the moral actor is never constrained by the moral knowledge of others, which would be the case if moral universals were upheld. Ultimately, each individual has the freedom under Kant to create a unique morality, the extent and quality of which is entirely specified by the rational capacity of the moral actor. For Kant, the individual creates the objective metaphysical moral order for the individual alone. 
Jeremy Bentham's moral system, utilitarianism, claimed to be objective to the extent that it rested on supposedly measurable quantities. However, the principle quantity, utility, is radically subjective and has created a mire of problems for its principle offshoot, contemporary economics. While it implicitly resting on the nature of goods and their comparability, it was argued by Bernard Williams to do little of what moral thought was expected to do, despite being the moral foundation for contemporary economics (Meikle 1995). Twentieth century moral thought has been pursued using various modern strategies but none of them have been able to provide a robust and comprehensive explanation of the common understanding of what ethics should include (Warnock 1967).

As a science of review, the place of ethics in the development of the practical science has also suffered in recent centuries. Aristotle introduced the study of economics as a part of his ethical thinking (Meikle 1995). Up until the beginning of the twentieth century economics was studied as a moral science under the name political economy. This meant that economics was recognised to be a practical science that operated within ethical parameters. Alfred Marshall argued that its moral purpose could be better pursued by concentrating on objective economic facts rather than ethical deductions and he recommended the positive science of economics. This implied an immense methodological shift for the science. No longer was economic thought reviewed within ethical criteria, even though it retained an ultimately ethical goal.

Marshall had succeeded in the Humean transformation of this particular ethical science into one that mimicked the natural sciences and their method. The positive economist does not engage in ethics, despite the science ultimately having an ethical end. Its ability to fulfil this role is sometimes questioned, such as by Ricardo Crespo (1998), but the mainstream reply is consistently in the negative (Boettke 1998). Crespo's contention was in line with Aristotle's view that saw ethics as primarily a principle for action for persons engaged in economic activity, not simply a policy goal. Marshall's argument reversed the emphasis and is consistent with the thrust of modern ethical thought which in practice stresses public ends over the inner dynamics of personal action. Modern social science considers the individual's ethics to be a given, that may be known only through observed action. With the passage time, this subtle debate regarding the relationship between economics and ethics, and its methodological implications, is being lost, especially with the low emphasis often accorded to the history of economic thought in undergraduate programmes.

This is not limited to economics, but can be seen in other practical sciences as well, such as political science (Barilleaux 2004). In law, the relationship between law and ethics has been debated fiercely for some time (Dworkin 1977). Positive law theory claims that law has no underlying metaphysics, while natural law theory recognises that the law has ethical roots that reach back into the implications of natures. Parallel to the moves alluded to by Boland, positive law theory appears to be currently losing ground to that based on natures (Mueller 2002). 
In all of these cases, it is apparent that ethics has been affected by different theoretical methodological positions and these have also affected how ethics is used in the methodology of practical sciences. Property economics is one practical science where these issues have been significant.

\section{THE METHODOLOGY OF PROPERTY ECONOMICS}

Property economics has largely adopted the methodological prescriptions applied to economics. Economics is dominated by a positive empirical approach which means that research and scholarship in the discipline is dominated by empirical methods. In practice this means an emphasis on empirical data, usually reviewed using mathematics or statistics. Metaphysics is almost irrelevant methodologically in the discipline, to the point that Boland could claim that few economists even know what metaphysics was or how it could be of importance to the discipline. Levy's (2003) survey of journals in the property economics area revealed that the overwhelming trend is towards quantitative statistical analysis of data derived from financial, property or opinion sources.

By contrast, the body of knowledge that represents the theoretical framework of the discipline is made up in no small measure of theories that were at least originally posited without formal empirical support. While some have since been validated empirically, many have not, at least unequivocally. Some of these have been already cited, such as supply and demand functions, but they also include the entire theory of the firm and specialised areas such as the capital asset pricing model and the suite of location theories that are found in urban economics. Usually these theories represent general tendencies subject to extensive sets of assumptions that appeal more to common sense than to rigorous scientific proof.

Economists have long argued that empirical evidence will eventually validate their theories, but practical evidence has been equivocal. A casual glance through any economics text book reveals an abundance of graphs demonstrating the behaviour of stylized economic systems, but almost none of them use unambiguous empirical data sets as validation. The fact that these theories, deduced as they are from metaphysical premises, are the substance of what is held as the body of knowledge for the discipline, held as true by practitioners and taught to students, is telling. There is something more fundamental and compelling in knowledge of this sort, compared to the results of statistical tests that tend to populate academic journals and research grant applications. Although they tend to follow from the metaphysical assumptions embedded in the foundations of the discipline, they are not proven as true in the manner demanded by science, but rather accepted as true by faith in the discipline.

The supposedly positively grounded mathematical representations of economic behaviour are in fact the result of abstraction from sufficient observation to inform a reasonable understanding of the natures involved. Their construction has more in common with the classical realist method of Aristotle, than with the empiricism of 
Machiavelli or Hume. Their adoption as the core knowledge of the discipline implies a fundamental respect for the classical methodology over the modern. This does not absolve economic theories from the obligation of being tested using observation, and this is always a necessary component in refining the precision of scientific knowledge. It tends to be in this second area that economics has the greater difficulty.

David Ling (2005) is representative of recent research that has thrown doubt on the validity of common forecasting methods. If economic theory cannot predict then, according to Friedman, it is a failure. William Grieder's account of the management of the US Federal Reserve through the decade to 1986 shows how little emphasis was placed on quantitative analysis by what is arguably the most influential financial entity in the world (Grieder 1987). If the Federal Reserve Bank resolves momentous practical economic decisions using conceptual debate between competing economic theories, it would appear to throw considerable doubt on their faith that positive methods are especially useful for prediction. Grieder's account of the practical operation of the Fed shows that it was competition between beliefs in opposing faiths regarding conceptual mechanics of the economy that occupied decision makers, not credible empirically validated predictions. Both academics and practitioners have apparently found that empirical methods have not delivered the results anticipated.

A major part of this problem may be traced back to the premises of the discipline. Economics is based on a particular type of economic actor, sometimes known as homo economicus. Unlike regular human beings, homo economicus is a rational, utility maximising individual. Homo economicus has the capacity to have perfect knowledge of markets and the ability to move frictionlessly in and out of them or from and in some cases from supply positions to demand positions. As rational, homo economicus is able to precisely quantify the utility of any economic good and its cost and will act with computer-like certainty towards optimal positions. Economics is also based the ethical system of utilitarianism. Neither of these premises equate well to the real world. A significant number of the economic theories that follow from them are also well known to differ from the actual casual mechanisms driving economic action. The marginalist theory of the firm has already been mentioned. The demand function has similar problems. Demand is notionally connected with the distribution of utilities through the market, with some purchasers perceiving greater utility from particular goods and consequently being willing to pay more for them. This is a necessary conclusion from homo economicus. Samuelson noted that the reality was not so much utility, but money, that drove demand when he noted "When the price of wheat is very high, only the rich will be able to afford it" with no reference to utility at all (Samuelson 1975). While demand also includes needs, it is money in the pockets of potential purchasers that ultimately shapes the function as what is more accurately termed "effective demand" (Sen 1981).

Problems of this kind resulted in Boland working through all of the theory of market economics as originally formulated by Marshall and concluding that there were major logical problems with much of it (Boland 1992). What Boland was in fact pointing out 
was that the causal mechanisms that supposedly gave rise to economic behaviour could not actually work because of internal contradictions. Milton Friedman's work on methodology, written almost forty years earlier, had previously accepted this problem and has been used to defend positive economics for the past fifty years. Friedman made the argument that it was effectiveness in predicting future outcomes, not alignment with actual causal mechanisms, that gave economics its validity as a science. Friedman even went so far as to claim that being interested a theory's alignment with reality "... is fundamentally wrong and productive of much mischief" (Friedman 1953, 14). Following Friedman means that an economist may invent any theory of economic action so long as it is capable of reasonable predictive success. Reflecting on the implications of Freidman's methodological approach, Morris Altman concluded that "Friedman's preferred methodological approach boils down to correlation analysis" (Altman 1999, p.432).

Economics as correlation analysis is now a commonplace. A cursory review of major property economics journals reveals that the majority are devoted almost entirely to quantitative studies and the majority of those are basically correlation. The difficulty is that the quantitative approach, along with most attempts at forecasting, has so far not lived up to expectations (Ling 2005). The answers cannot lie with more data analysis, but rather with better and more appropriate theories drawn from a revived interest in the metaphysics that underlies the science and the programmes adopted for testing them. However this approach is often barred from scholarly journals where classical argumentation is softly rejected as theoretical opinion pieces or pejoratively as only big essays without research rigour (i.e. numbers). This approach may work for a time, so long as there are sufficient theoretical resources to fuel quantitative testing programmes, but it lacks the intellectual vigour to genuinely move the science forward.

Of greater potential concern to economists is the charge that the discipline is not really a science at all. This is made both by natural scientists and the general population, usually for different reasons. Natural scientists can justifiably look at economics and see a discipline that is not interested in causality and whose conclusions do not stand up to the analytic scrutiny that even its own practitioners recommend. As science, it is becoming a grand correlation study that shuns a realistic conceptual mapping of its object. Its interest in causality is comparable to astrology, or at best to Ptolemy's astronomy. Ptolemy's astronomy was at least a reliable system for predicting astronomical events at modest accuracy; economics has not risen to that level of performance.

The community recognises the contradictory array of economic systems and predictions that makes in-fighting a major reason to be suspicious of the discipline as a whole. More generally, the average person has good cause for agreeing with the title "the dismal science" that economics has earned for itself on the basis that a suspicious majority of the policy recommendations of economic analysis tend to mean substantial additional hardships for the majority in order to accrue any economic gain (Pusey 2003).

In part, the modern tendency to follow Hume's view that only empirical sciences have merit is responsible for an overly narrow methodological perspective. In hoping to make 
economics more scientific, people such as Marshall and Freidman have in fact ensured that it would eventually fail any real test that a genuine science should be able to pass. Implicitly economics has retained a metaphysical foundation, but its appropriateness is questionable (Boland 1997). While economics continues to limit its methodological possibilities so narrowly that the fundamental questions are excluded from the discipline's central literature and research programmes, it continue to develop as a myopic pursuit of competing ideologies and petty positive findings. About the edges of the discipline have arisen a mass of reactionary and often faulty attempts to broaden the scope of the science. These tend to exist as books rather than academic journal articles, indicating that it is easier to find a popular audience who share disillusion with the discipline rather than to engage in scholarly dialogue with it. Economics currently stands as an illustration of Thomas Kuhn's contention that established disciplines tend to discourage enquiry outside the acceptable limits of the paradigm set by its peers, regardless of where truth lies (Kuhn 1970).

The mainstream economics discipline behaves in this way, often using a provincialist straw man argument to imply that all non-mainstream authors have socialist leanings that are political in nature and faulty in execution. The reality is more complex. Currently the loose body of economic thought that opposes mainstream economics often uses the title heterodox economics, and little of it is socialist, especially in the tradition of Des Kapital. Heterodox economics can be thought of as a speculative area in economics that attempts to explore more realistic theories of economic action with a view to enlarging the frame of reference of the science and making it more robust. To do this heterodox economists tend to pursue methods of the behavioural sciences, philosophy, and ethics.

\section{PROPERTY ECONOMICS RESEARCH}

Property economics shares much of this problematic methodological narrowness. Methodological rigour in the discipline is often confused with statistical rigour, making it a proof case of Altman's view that correlation, usually as regression, defines knowledge acquisition. The range of quantitative methods available has been constrained by the lack of metaphysical insight. Regression analysis remains the dominant analytic tool, yet the causal connections assumed away in the common arbitrary strategy of assuming simple (usually linear) connections, threaten the scientific integrity of the result. Regression as a tool is conceptually more suited to mass appraisal research than time series forecasting, yet it dominates that sphere of research.

The equivocal success of these approaches is becoming apparent with (Ling 2005) recognising that forecasts do not have sufficient quality to significantly add value to investment decisions. Likewise, the repeated failure of the RICS model in Australian markets would appear to be more probably connected with the nature of the model than data imprecision as suggested by John MacFarlane (2001; 2002). It would explain why Paul Gallimore and Patrick McAllister (2004) found that in practice professional 
forecasters place personal opinion above quantitative methods in publishing predictions of the future.

Regression analysis is not suited to data sets that display multicollinearity and autocorrelation. In order to apply regression to these situations the data has to be transformed to remove these influences, but the transformations compromise any connection with causality. It may be argued that one factor, say interest rates, has a linear effect on another, say house prices, but if it is necessary to transform interest rates and perhaps house prices, say by taking first or even second differences, logarithms and various lags, the causality story becomes progressively more tenuous. The practical object tends to contract to finding mathematical systems that approximate to history. The fundamental question of inductive forecasting becomes more exposed: "will the future be like the past?" The problem with an affirmative answer is that it confuses those cases where it does due to defensible causal understanding, say the case of the sun rising each day, with mere past common coincidences generated by complex mathematical manipulation of reluctant data.

Harmonic analysis is a good case in point. Mathematicians have long known that any temporally limited pattern of fluctuations can be modelled precisely using a compound of sine curves at various harmonics. This means that any pattern of historical data can be modelled using harmonic analysis (sometimes known as spectral analysis). What is not certain however, is whether the resultant harmonic function has any certain relationship to the behaviour of the variable outside the original temporal limits. Experimentation with harmonic analysis as a forecast tool, while mathematically stimulating, reveals an indifference to causality and a blind faith that the future will happen to coincide with a continuation of an extremely complex mathematical equation that has no conceptual causal relationship to the objective processes. Neural network analysis shares the same conceptual flaw and shares the further dubious distinction that it was the product of a line of psychological research into the operation of the brain that has subsequently been discarded by psychology. It survives merely as a computer algorithm that appears to learn from partially inconsistent data. Its application to property research (Kim and Nelson 1997; Flaherty, Lombardo et al. 1999; Sarip 2005) is evidence of an emphasis in property economics on predictive ability with no anchoring in causality.

The Friedman/Altman controversy regarding economic methodology sits just below the surface here with the practical research intent being only on correlation and not on causality. An investigation of the natures of the various components of economic time series data, their causality and the quantitative tools used to model them, along the lines of metaphysical enquiry has the capacity to inform this situation, but it remain outside the formal gamut of property economics discourse. Economic time series data are of a form that, of their nature, could be expected to fluctuate in a manner that makes forecasting very difficult. This is because the system is of a type where the present values of the various variables are most probably functions of previous values of themselves and other variables in the system. 
Economic actors make moderately rational decisions on the basis of their reading of various economic and financial data and trends. To the extent that they are rational, it should be possible to show that they follow decision rules that can be mapped into mathematical algorithms. In sum, the various algorithms used by the different actors would define all the variables in the market. If this is a fair description of the economic/financial environment, James Gleick (1987) demonstrated that there are at least three different ways such an interrelated mathematical system could behave. It can trend towards a steady state, or regular oscillations, or fluctuate in a complex and continuously irregular fashion bounded by vague limits on amplitude and frequency. Much economic theory assumes the first (equilibrium theorists), recent forecasting interest attempts to reveal the second (cycles theorists), but such a system could easily display the irritatingly unexpected fluctuating behaviour that is what many consider the common experience.

The problem is that if economic and financial systems do have the actual causal relationships that map into this type of mathematical algorithm, then the actual style of behaviour (equilibrium, cyclic, or random fluctuations) may ultimately depend merely on slight variations in the coefficients in the mathematical relations between variables. The insight to recognise this fact is the forte of the pure mathematician, not the statistician, the Freidmanite economist, or the practicing forecaster who ices the quantitative cake with gut feel in order to produce a marketable product. It would suggest that there is a place for the methodology of pure mathematics in the development of practical property economics research.

There are other similar opportunities for methodologies from other sciences to inform the future direction of the property economics discipline. In some cases these have successfully gained a foothold in the public discourse of the discipline. The next section will survey some of the methodological approaches that have had some success in expanding the methodological paradigm of the discipline.

\section{EMERGING METHODOLOGIES}

An enlarged understanding of where property economics stands within the spectrum of practical sciences permits a wider range of methodological possibilities. Some of these have already begun to find their way into the discipline.

Behavioural property has been championed by Julien Diaz $(1990 ; 1999 ; 2004)$ and is now associated with researchers including Paul Gallimore $(1994 ; 1996 ; 2000 ; 2004)$ and Deborah Levy (1999; 2005), amongst others. It has successfully introduced psychological methods, recognising that property actors are humans who exhibit irrational, though sometimes consistent, behaviour. While economics stresses market data, the property behaviourists stress human action. In so doing they are able to utilise experiments, interview techniques and other methodological approaches that have been 
long established in psychology and sociology. The insights from behavioural property are realistic, practical and challenge many assumptions foundational to economics.

Property is determined by legal and cultural parameters. Austin Jaffe (1996; 1998) argued that institutional factors relating to the nature of property rights in particular societies had great bearing on its economic use. In doing so he represents an approach to property economics research that explores the nature of property as property rights. The RICS "Our Common Estate" series can be viewed as an instance of this institutional approach. The 2002 South Pacific Land Tenure Conflict Symposium drew strong support from the UN and high level South Pacific government agencies to explore institutional issues that were affecting property economic issues in that region. The methodologies appropriate to investigation of property as an institution include positive economic investigation, but stress social, anthropological and political science approaches that have been alien to the discipline.

The institutional perspective turns attention to the fact that property markets operate within legal frameworks and institutional change often follows legal developments. This fact suggests the appropriateness of legal methodologies as fundamentally important in the understanding of property markets. John Sheehan $(2000 ; 2001 ; 2005 ; 2005)$ has used this approach successfully in developing the property economics of a number of difficult aspects of property rights, their pricing and their administration. The methods of legal scholarship stress deductive argument resting on social, anthropological historical and ethical premises. While it has been alien to recent developments in economic methodology, it connects strongly with classical economic thought, suggesting the enduring importance of those aspects of economic scholarship what were formally excised from the discipline in its transition from political economy to economics by theorists such as Marshall.

Beyond the law, Small (2003) argued that law itself rested on foundations that included cultural, ethical, anthropological, theological and metaphysical conclusions that all contributed to the institution of property. This would suggest that a thorough understanding of the operation of property economics in a particular institutional context could be informed by methodological approaches employed by any of these sciences.

Within the broad fields summarised above there are a wide range of methodological possibilities that include those associated with many of the social sciences and even branches of pure philosophy and theology. While many questions in the discipline may not require the more exotic possibilities, their possible applicability makes it inappropriate to dismiss them out of hand, as appears to have been the case in recent times. In this way, the discipline can respond to Austin Jaffe's (1996) concern that due to its dependence on economic and financial theory and method, it really had little claim to be considered as an independent discipline. On the contrary, Max Kummerow (2002) argued that property economics, while intimately related to economics, had an interest in realism that has the capacity to inform and perhaps invigorate the parent discipline. It can only do this by bringing insights and methods from beyond the parent discipline to the table. By contrast, economics, especially that subset of economic thought that is currently 
taught in most western universities, runs the risk of becoming more ossified within a framework of theories that have been betrayed by positive research too often to be adopted as anything more than risky approximations.

\section{CONCLUSIONS}

Property economics has adopted the narrow methodological prescriptions of general economics. While this has been powerfully argued by prominent economists, it is now becoming apparent that it is insufficient for the needs of the discipline. To broaden the methodological basis of the discipline it will first be necessary to reintroduce explicit investigation into its metaphysics. This necessarily requires non-empirical methodologies and preferably a more comprehensive understanding of what science is, how it works and how property economics is located within it. The recent emergence of alternate property systems associated with indigenous people is one instance of a fundamental issue in property that its dominant methodological system is incapable of adequately responding to. Even within the use of mathematical modelling it has been shown that the underlying metaphysical realities are sufficient to cast serious doubt on currently popular research tools.

Other disciplines within the practical sciences, such as law, use very different methodological approaches. Scholarship within those disciplines appears to be quite solid and possibly even better aligned to their scientific objects. The narrow quantitative bias found in the public discourse of the property economics discipline reflects an equally narrow, perhaps even non-existent, understanding of the scope and importance of methodology. Without a conscious broadening of this position, any real progress in the discipline may only happen by chance. By tapping into the intellectual patrimony of our own cultural heritage, methodological insights are available that could form the basis for genuine advances and the establishment of the discipline as a genuine practical science.

\section{REFERENCES}

Altman, M. (1999). "The Methodology of Economics and the Survivial Principle Revisisted: Some Welfare and Public Policy Implications of Modeling the Economic Agent." Review of Social Economics 57(4): 427-449.

Ashley, B. (2003). Dominican Guide for sharing our secular Resources for the Study of theology for Preaching in the Twenty-first Century, www.op.org/domcentral/study/ashley/guide/dominicanguide.pdf. 2005.

Barilleaux, R. J. (2004). "The Restoration of Political Science." The Catholic Social Science Review 9: 129-146. 
Boettke, P. J. (1998). "Is Economics a Moral Science? A Response to Ricardo F. Crespo." Markets and Morality 1(2): 212-219.

Boland, L. A. (1992). The principles of economics : some lies my teachers told me. London, Routledge.

Boland, L. A. (1997). Critical Economic Methodology: a personal odyssey. London, Routledge.

Crespo, R. F. (1998). "Is Economics a Moral Science?" Markets and Morality 1(2): 201-211.

Diaz, J. (1990). "The Process of Selecting Comparable Sales." Appraisal Journal 58: 533-540.

Diaz, J. (1999). "The first decade of behavioral research in the discipline of property." Journal of Property Investment \& Finance 17(4): 326-32.

Diaz, J., P. Gallimore, et al. (2004). "Multicultural examination of valuation behaviour." Journal of Property Investment \& Finance 22(4/5): 339.

Dworkin, R. M., Ed. (1977). The Philosophy of Law. Oxford, Oxford University Press.

Flaherty, J., R. Lombardo, et al. (1999). A Spreadsheet Approach to Business Quantitative Methods. Melbourne, RMIT.

Foucault, M. (1976). Disciplinary Power and Subjection. Power/Knowledge: Selected Interviews and Other Writings 1972-77. C. Gordon, Pantheon.

Friedman, M. (1953). The Methodology of Positive Economics. Philosophy and Economic Theory. F. Hahn and M. Hollis. Oxford, Oxford University Press: 18-35.

Gallimore, P. (1994). "Aspects of Information Processing and Value Judgement and Choice." Journal of Property Research 11: 97-110.

Gallimore, P. (1996). "Confirmation bias in the valuation process: a test for corroborating evidence." Journal of Property Research 13(4): 261 - 273.

Gallimore, P. and P. McAllister (2004). "Expert judgement in the processes of commercial property market forecasting." Journal of Property Research 21(4): 337 - 360.

Gallimore, P. and M. Wolverton (2000). "The objective in valuation: a study of the influence of client feedback." Journal of Property Research 17(1): 47 - 57.

Gleick, J. (1987). Chaos. London, Cardinal. 
Grieder, W. (1987). Secrets of the Temple. New York, Simon \& Schuster.

Harvey, J. (1987). Urban Land Economics. London, Macmillan.

Hirsch, E. D., Ed. (2002). The New Dictionary of Cultural Literacy, Houghton Mifflin.

Hume, D. (1777). Enquiries concerning Human Understanding and Concerning the Principles of Morals. Oxford, Claredon.

Jaffe, A. (1996). Presidential Address. American Real Estate and Urban Economics Association Annual Meetings, Washington DC.

Jaffe, A. J. (1998). The Costs Of Ignoring Institutional Factors In International Property Research. Pacific Rim Real Estate Society Conference, Perth.

Jaffe, A. J. and D. Louziotis, Jr. (1996). "Property Rights and Economic Efficiency: A Survey of Institutional Factors." Journal of Real Estate Literature 4(2): 137-59.

Jones, R. (1976). Supply in a Market Economy. London, Allen and Unwin.

Kant, I. (1785). Grounding for the Metaphysics of Morals. USA, Hackett.

Kim, K. S. and W. A. Nelson (1997). "Assessing the Rental Value of Residential Properties: An Abductive Learning Networks Approach." The Journal of Real Estate Research 12(1): 63-77.

Kuhn, T. (1970). The Structure of Scientific Revolutions. USA, University of Chicago Press.

Kummerow, M. (2002). The Scope and Method of Political Economy, 2002, Pacific Rim Real Estate Society.

Levy, D. and M. Henry (2003). "A Comparative Analysis of US, UK and Australian Published Property Research Methodologies and Methods." Pacific Rim Property Research Journal 9(2): 148-162.

Levy, D. and E. Schuck (1999). "The Influence of Clients on Valuations." Journal of Property Investment and Finance 17: 380-400.

Levy, H. and M. Levy (2005). Overweighing Recent Observations: Experimental Results And Economic Implications. Experiential Business Research. R. Zwick and A. Rapoport. Dordrecht, Springer. 
Ling, D. C. (2005). "Random Walk Down Main Street: Can Experts Predict Returns on commercial Real Estate." Journal of Real Estate Research 27(2): 137-.

MacFarlane, J., J. Murray, et al. (2002). Forecasting Property Market Cycles: An Application of the RICS Model to the Sydney CBD Office market. Pacific Rim Real Estate Society annual conference, Christchurch NZ.

MacFarlane, J., D. Parker, et al. (2001). Forecasting Property Market Cycles: An Application Of The RICS Model To Australian Property Markets. Seventh Annual Pacific Rim Real Estate Society Conference, Adelaide.

Machiavelli, N. (1985). The Prince. Chicago, University of Chicago Press.

Marshall, A. (1890). Principles of Economics. London, Macmillan.

Meikle, S. (1995). Aristotle's Economic Thought. Oxford, England, Oxford University Press.

Mueller, J. D. (2002). The Return of Natural-Law Economics. Colloquium on the American Founding, Amherst University.

Plato (1987). The Rebublic. London, Penguin.

Pusey, M. (2003). The Experience of Middle Australia. Cambridge, GB, Camridge University Press.

Samuelson, P. A. (1975). Economics. Sydney, McGraw Hill.

Sarip, A. G. (2005). Integrating Artificial Neural Networks And Gis For Single-Property Valuation. Pacific Rim Property Research Conference, Melbourne, PRRES.

Sen, A. K. (1981). Poverty and famines : an essay on entitlement and deprivation. Oxford, England, Oxford University Press.

Sheehan, J. (2000). "Assessing Compensation for Native Title: A Valuation Perspective." Pacific Rim Property Research Journal 6(1): 43 - 56.

Sheehan, J. (2001). "Indigenous property rights and river management." Water Science and Technology 43 (9): 235-242.

Sheehan, J. (2005). "The Commodification of the Asian Commons: Water as a Property Right." Asia Pacific Journal of Environmental Law 9(1): 87-103. 
Sheehan, J. and G. Small (2005). "Water Property Entitlements and Biota Property Rights." Spatial Science Queensland 2005(2).

Small, G. (2003). "Human action and Property." Pacific Rim Property Research Journal 9(4): 348-60.

Warnock, G. J. (1967). Contempory Moral Philosophy. London, McMillan.

Weaver, R. M. (1948). Ideas Have Consequences. Chicago, IL, University of Chicago Press.

Wilson, C. and B. Keers (1990). Introduction to Financial Management. NY, Prentice Hall.

Working, E. J. (1927). "What do Statistical "Demand Curves" Show?" The Quarterly Journal of Economics, Vol. XLI (1927),: 212-235. 